\title{
Necrotizing Fasciitis Due to Serratia marcescens Infection Following Snake Bite
}

\author{
Muthu Chidambaram ${ }^{1}$ [ $\cdot$ Melachuru Sai Padma Charan ${ }^{1} \cdot$ Karra Saraga $^{1} \cdot$ Jai Durairaj Paramasivam ${ }^{2}$. \\ Balamma Sujatha ${ }^{1}$
}

Received: 14 August 2021 / Accepted: 12 November 2021/Published online: 8 January 2022

(c) Dr. K C Chaudhuri Foundation 2021

To the Editor: A 3-y-old boy was brought to the emergency room with alleged history of snake bite $1 \mathrm{~h}$ back, followed by pain and swelling in the left calf region. Examination showed swelling along with two fang marks in the left lower limb. Whole blood clotting time was normal. Subsequently, the child developed ptosis and respiratory failure, and was intubated and started on mechanical ventilation. Antisnake venom was given and he was extubated within $12 \mathrm{~h}$.

On day 2 , the child developed fever along with increase in the size of the necrotic area and swelling of the involved leg. His CRP was $336 \mathrm{mg} / \mathrm{L}$. Inj. amoxycillin clavulanic acid was started in view of probable infectious cellulitis. The swelling and necrosis worsened in spite of antibiotics. So necrotizing fasciitis was suspected and the child was taken up for debridement. Tissue culture showed growth of Serratia marcescens and antibiotic was upgraded to piperacillin and tazobactam, based on sensitivity pattern. The child underwent extensive multiple debridement, and repeat wound swab was negative. On day 25 , a split skin grafting was done.

Serratia marcescens is an uncommon cause of cellulitis following animal bite. Oral cavity of a snake is colonized by various bacteria especially the gram-negative Enterobacteriaceae family. Grim et al. [1] and Pithadia et al. [2] described Serratia marcescens infection following lizard bite and dog scratch, respectively. Similar to our case, Subramani et al. [3] reported a case of bullous cellulitis caused by serratia following unknown snake bite in an adult from India.

To conclude, in nonresolving or progressive course of local complications following snake bite, infectious etiology should be considered in addition to the toxin-induced damage. To our knowledge, this is the first case of necrotizing fasciitis caused by Serratia marcescens following snake bite in pediatric population.

\section{Declarations}

Conflict of Interest None.

\section{References}

1. Grim KD, Doherty C, Rosen T. Serratia marcescens bullous cellulitis after iguana bites. J Am Acad Dermatol. 2010;62:1075-6.

2. Pithadia DJ, Weathers EN, Colombo RE, Baer SL. Severe and progressive cellulitis caused by Serratia marcescens following a dog scratch. J Investig Med High Impact Case Rep. 2019;7:2324709619832330.

3. Subramani P, Narasimhamurthy GB, Ashokan B, Madappa BP. Serratia marcescens: an unusual pathogen associated with snakebite cellulitis. J Infect Dev Ctries. 2013;7:152-4.

Publisher's Note Springer Nature remains neutral with regard to jurisdictional claims in published maps and institutional affiliations.

Muthu Chidambaram

dr.muthu87@gmail.com

1 Department of Pediatrics, Saveetha Medical College and Hospital, Chennai, Tamil Nadu 602105, India

2 Department of Pediatric Surgery, Saveetha Medical College and Hospital, Chennai, Tamil Nadu 602105, India 